\title{
Does the EVA valuation model explain the market value of equity better under changing required return than constant required return?
}

\author{
Sujata Behera
}

Correspondence: sujatadalai2014@ gmail.com

Institute of Management, Nirma University, B-301 Aditya Greens, Near Sahajanand City Bunglow, Near Sona Cross Road, New C. G Road, S.G. Highway, Ahmedabad, Gujarat 382424, India

\begin{abstract}
Through the Economic-Value-Added (EVA) valuation model, the expected market value of equity can be determined by adding the book value of equity with the present value of expected EVAs under the assumption of constant required return and constant return on equity. The equation of EVA valuation model has taken its shape under the assumption of constant required return and constant return on equity. However, a large body of empirical evidence indicates that required rate of return never remain constant. The EVA-valuation model formulated under constant required return cannot be implemented under the scenario of changing required return. In this study, we explored whether the EVA valuation model could be implemented under changing required return by making any changes in the model and found that it could be implemented under the scenario of changing required return by replacing the book value of the equity of the existing model with the present value of required earnings or normal market earnings. We further examined whether the explanatory ability of the EVA valuation model under the assumption of changing required return is better than that of the valuation model under the assumption of constant required return. Relative information content analyses were conducted by considering sample of the intrinsic value of equities determined by valuation models and the market value of equities of 69 large-cap, 88 mid-cap, and 79 small-cap companies. The results showed that the EVA-based valuation model with changing normal market return outperformed the EVA-based valuation model with constant required return.
\end{abstract}

Keywords: Economic value added (EVA), Capital asset pricing model (CAPM), Expected market value of equity under constant required return (EMVEUCRR), Expected market value of equity under varying required return (EMVEUVRR)

\section{Introduction}

Valuation is an important topic in finance, as it is needed for companies to get their equity capital valued for purposes such as borrowing, merging, acquiring, and making public offerings. The importance of valuation in attracting foreign investments has grown in emerging economies such as that of India. Even so, the rising globalization, market liberalization, and drastic competition have made it difficult for academics,

(C) The Author(s). 2020 Open Access This article is distributed under the terms of the Creative Commons Attribution 4.0 International License (http://creativecommons.org/licenses/by/4.0/), which permits unrestricted use, distribution, and reproduction in any medium, provided you give appropriate credit to the original author(s) and the source, provide a link to the Creative Commons license, and indicate if changes were made. 
practitioners, company owners, managers, and consulting firms to accurately estimate the value of equity.

The shareholders' value theory places shareholders at the top of a hierarchy in analyzing the economic performance of a business. The EVA is a modified version of the shareholders' value theory (Banerjee, 2000). The selling point of EVA is that it increases stock return. It also stands out from the crowd for its association with stock prices. As such, EVA gained popularity toward the end of the twentieth century, most notably when the executives of big companies such as AT\&T and Coca-Cola publicly declared that a 27\% rise in EVA performance increased stock return by about 200\% (Chen and Dodd, 1997). Moreover, an article in Fortune magazine praising EVA as a measure of corporate success attracted a flurry of research papers that detailed EVA success stories and promoted EVA adoption (Chen and Dodd, 1997). A huge body of literature isnow available on success stories of the EVA model. EVA performs better than accounting measures in explaining stock return (Behera, 2019; Gounder and Venkateshwarlu, 2017; Khan et al., 2016; Ahmed, 2015; Bhasin, 2013; Zhao and Wang, 2012; Worthington and West, 2004; Misra and Kanwal, 2007; Singh, 2005; Lefkowitz, 1999; Saxena, 1998; Easton et al., 1992).

EVA advocates have claimed that upward and downward trends in stock prices are strongly associated with EVA. Some found that EVA could be used to more accurately determine the intrinsic value of equity by adding the book value of equity with the present value of EVAs under the assumption of constant required return and constant return on equity (Stewart, 1991). Later, O'Byrne et al. (1996) found that EVA better predicted the expected market value of equity by adding the book value of equity capital, the perpetual value of the current EVA, and the present value of the perpetual value of incremental EVAs generated by future invested capitals under the assumption of constant required return and constant return on invested capital. Despite these success stories of using EVA as performance measurement metric, little attention has been paid to examining the efficiency of the EVA valuation model. Using an EVA valuation model formulated with the assumption of constant normal market return raises the question of whether the normal market return remains constant. Growing empirical evidence hints at the volatility of financial return and emphasizes that the relative importance of the volatile component of competitive advantage rises when compared to the long-run component of the sustainable competitive advantage (Thomas and D'Aveni, 2009). Normal market return never remains constant, and asset values are better explained under time-varying discount rates than under constant required return (Campbell and Mei, 1993; Mei and Lee, 1994; Ahrendsen and Khoju, 1994; Geltner and Mei, 1995; Saha and Malkiel, 2012; McLemore et al. 2015; Gelter and Mei, 1995; Ang and Liu, 2003). Similarly, D'Aveni et al. (2010) explained that the environment has become more dynamic and disruptive because of technological change, globalization, industrial convergence, aggressive competitive behavior, deregulation, the privatization movement stimulated by government or hedge funds, government subsidiaries, the rise of emerging economy, and global political instability. The drastic competitive actions and counter responses among rivals have increased the volatility of financial returns. In the current market scenario, expecting constant return on investment equity capital is unrealistic. Thus, an EVA valuation model that 
operates under the assumption of constant required return and constant return on equity cannot be implemented under the scenario of a changing required return.

To address the above limitations, we first posited that the book value of equity of the existing EVA-based valuation model needs to be replaced with the present value of normal market earnings in order to implement the valuation model under the scenario of changing required return. Next, we examined whether the assumption of changing the normal market return leads to a better estimation of the intrinsic value. Therefore, this study compared the explanatory ability of the EVA-based valuation model operating under a changing required return with the explanatory ability of the existing EVAvaluation model that operates under a constant required return. To stay focused on the objective, this study did not include a deeper discussion on how the discount rate changes over time. We made this choice because finance is all about practical application, not just deep explanation (Cochrane, 2011). Moreover, discount return variation can significantly change application (Cochrane, 2011).

We determined the required rate of return or normal market return in two different ways: a static estimate with no variation in risk-free return, the market premium, and the beta over the periods of each company; and a variable estimate with periodic variation in risk-free return, the market premium, and the beta. For better exposition, this study considered sample data from over 15 years (from 2002 to 2003 to 2016-2017) of 69 large-cap, 88 mid-cap, and 79 small-cap companies, and included a relative information content analysis. The results of the analysis indicated that the explanatory ability of the EVA-based valuation model is better under changing required return than under constant required return.

The rest of this paper is organized as follows. Section 2 describes the existing literature on EVA and the gap. Section 3 discusses the derivation process of EVA and the EVA valuation model. Section 4 includes our hypothesis. Section 5 covers the data source and sample selection. Section 6 reports the results and focuses on the overall discussion. Section 7 provides the conclusion.

\section{Literature review}

Value is the primary concern of investors and managers. Performance measures play an important role in creating value for organizations. However, it is a difficult task for management to select an appropriate performance measure that accurately measures the performance of the organization over a specific period of time. Traditional accounting measures have been roundly criticized for not considering the total cost of capital.

To overcome this limitation, Stewart (1991) proposed the concept of EVA, which is unique in the market because it considers the cost of capital. It determines extra earnings over normal market earnings or required earnings with the objective of evaluating the performance of company with respect to the market over a specific period of time, where normal market earning is determined by multiplying the normal market return with the book value of invested capital. Moreover, EVA compares company-specific earnings with required earnings or normal market earnings. Therefore, an adjustment to one comparable factor of EVA (as suggested by Stewart in 1991) may cause an imbalance in the comparative ability of earnings and normal market earnings, which can in turn reduce accuracy. Thus, it is necessary to ensure the calculation of the cost of capital and adjustments to the accounting profit in such a manner that year-to-year 
comparison accurately measures the performance (Chamberlain and Campbell, 1995). To calculate EVA accurately, actual accounting earnings should be considered instead of adjusted operational earnings (Young, 1999; Chen and Dodd, 1997; and Raman, 2004). Accounting earnings explain the equity return and market value of equity better than adjusted net operational earnings (Biddle et al. 1997; Dodd and Chen, 1997; and Ramana, 2005). There is no theoretical or empirical evidence to suggest that EVA adjustments can convert an incorrect accounting number into a correct estimated value, just as there is no economic theory guiding the selection of the most relevant accounting variables to adjusted (Anderson et al., 2004).

EVA adjustments make EVA too complex, and it is easily manipulated (Azamhuzjaev and Mackey, 2001). In addition, adjustments to net operating income may remove accruals that are used by the market to find the future prospectus of companies (Biddle et al., 1997). The data necessary to make the adjustments are difficult to obtain (Petersons and Peterson, 1996). Moreover, the results of adjustments depend on assumptions and judgments, which can vary from company to company, making it difficult to conduct reliable comparisons (Cates, 1997). In this study, we attempted to incorporate the suggestions of the above researchers by considering the accounting rate of return on the book value of equity in place of the adjusted operating rate of return. To keep normal market return at the same level as the accounting rate of return, we used the capital asset pricing model (CAPM) model, with some variation to compute required rate of return/normal market return. Instead of using annual capital growth rate as " $\mathrm{r}_{\mathrm{m}}$," this study considered the accounting return on the book value of equity of SENSEX as " $r_{m}$."

Several studies have been conducted on EVA during the last two-and-half decades to examine its efficiency as a periodic performance measure. Behera (2019) conducted a study on 69 large-cap companies selected from the BSE 500 and compared the efficiency of EVA with accounting measures in explaining stock prices. The results showed that EVA maintained a strong association with the stock price and yielded incremental information content beyond that provided by other accounting measures. Similarly, Ellanti (2016) conducted a study by considering 197 sample companies from BSE over the period of 2010-2014 using a univariate linear regression and multiple regression analyses. Khan et al. (2016) conducted a study that considered samples selected from 28 non-financial firms listed in the Karachi Stock Exchange and found that EVA availed incremental information content beyond the information content given by earnings. Ahmed (2015) conducted a study on five Bangladeshi companies and found that EVA maintained a significant association with stock price. Similarly, Bhasin (2013) examined five Indian companies through data from 2006 to 2007 through 2010-2011 and found that the explanatory ability of EVA was better than that of traditional performance measures. Kumar and Sharma (2011) considered a sample from the BT 500 and reported that EVA had incremental information content in addition to the information content of the earnings. Mishra and Kanwal (2005) examined the relationship between share price between EVA and traditional measures using BSE-100 companies from 1998 to 2003 and concluded that EVA maintained a better association with share price compared to traditional measures.

EVA proponents have claimed that EVA is the only performance measure directly tied with a stock's intrinsic value (Stewart, 1991). Successful stories of well-known 
companies such as AT\&T, Briggs \& Stratton, Chrysler, Compaq, GE, Quaker Oats, and Scott Paper have popularized EVA (Tully, 1993) Large-, mid-, and small-cap companies that have been attracted by all these success stories have adopted EVA. More than 300 companies, each with revenues approaching one trillion dollars annually, have implemented EVA as a financial performance measurement tool (Ehrbar, 1998). The reason for this trend is that EVA motivates companies to find ways of increasing the efficiency of capital utilization and can consequently bring about a superior stock performance (Tully, 1993). Tully (1993) explained that EVA has been gaining in popularity since September 1993 following an article in Fortune magazine that strongly praised EVA as an exciting innovation that could measure corporate success. Similarly, O'Byrne et al. (1996) advocated that EVA, unlike NOPAT and other accounting measures, is systematically linked to market value.

EVA advocates have also claimed that the measure can motivate companies to find ways of increasing capital utilization and bring stock performance. For example, Chen and Dodd (1997) used the Stern Stewart database, containing EVA performance on 1000 leading U.S. companies, and found that EVA had better explanatory ability than regular accounting measures. Lehn and Makhija (1997) conducted a study of 241 U.S. companies over the periods 1987-1988 and 1992-1993 and observed that both MVA and EVA were positively correlated with stock returns; moreover, the correlation of EVA with stock return was marginally better than that for accounting measures. EVA explains market value better than accounting measures (Kukreja and Giridhar, 2005; Mangala and Joura, 2002; Singh and Garg, 2004; Singh and Mehta, 2012). Its adoption also helps companies increase their stock price (Ethiraj, 1998). Banerjee (2000) conducted a study of 200 Indian companies across industries using a sample over the period of 1993-1998 and observed that the market value of firm could be well predicted by the discounted value of expected EVAs. The popularity of EVA has notably increased in India. Here, companies including Infosys Technologies, BPL, HUL, NIIT, TCS, Godrej Consumers Product Limited, Ranbaxy Laboratories Ltd., and Samtel India Limited have all reported EVA in their financial statements.

EVA not only more accurately measures the performance of a company but also predicts the market value of equity by adding the book value of equity with the present value of expected EVAs under the assumption of constant required return and constant return on equity (Stewart, 1991). Despite a huge body of literature claiming that EVA has a strong association with stock value, very little study has been conducted on a suggested EVA-based valuation model. A valuation model plays a vital role in determining the time of buying and selling investor securities. Fundamentally, analysts believe that intrinsic values, which aid in the process of borrowing, merging, and acquiring, determined by valuation models are the actual value of equity. Higher and lower intrinsic values indicate corporate performance. As a developing country, India is in great need of a proper valuation model to attract foreign funding. Therefore, implementing a proper valuation model is highly important.

The growing popularity of EVA in India and the growing need for a proper valuation model encouraged us to focus our study on EVA-based valuation. The EVA-based valuation model is derived from the addition of the current operational value and the future growth value, where the future growth value is the present value of incremental EVAs generated by future invested capitals (O'Byrne et al., 1996). Moreover, both the current 
operational value and the future growth value are derived from Modigliani and Miller's equations, proposed in 1961. The current operational value, e, was derived from the first part of Modigliani and Miller's equation, which is NOPAT/C; the future growth value was derived from the second part of the equation, which is $\sum[\mathrm{I}(\mathrm{r}-\mathrm{c}) / \mathrm{c}] /(1+\mathrm{c})^{\mathrm{t}}$. In this equation, $r$ is the return on new invested capital, $c$ is the weighted average cost of capital, and I is the new invested capital. O'Byrne et al. (1996) suggested that the expected market value can be determined by adding the book value of invested capital, the perpetual value of the current EVA, and the present value of capitalized incremental EVAs expected to be generated by future invested capital under the assumption of a constant normal market return and a constant return on invested capital.

The assumption of a constant normal market return and a constant return on equity of existing EVA-based valuation raises the following questions:

1. Does normal market return remain constant?

2. Do corporations provide a constant return to their investors?

There is growing empirical evidence to suggest that the volatility of financial returns is increasing. Most literature supports the presence of high competition, the volatility of financial returns, and the volatile component of competitive advantage, and it suggests that a sustainable advantage does not necessarily exist, except dynamic capabilities and organization flexibility can occasionally be sources of a sustainable advantage (D'Aveni et al., 2010). Thomas and D'Aveni (2009) used different methods that decomposed accounting returns into long- and short-term components and observed that the volatility of performance increased in the U.S. over time. They also found that volatility of returns rose from 1950 to 2002 for all traded U.S. manufacturing firms. Furthermore, volatility has been found to rise in earnings, sales, employment growth, capital expenditure, and the total factor of productivity (Comin and Mulani, 2006; Comin and Philippon, 2005). Severens and Milen (2004) explained that the consistent principle for finding the discounting factor internationally or nationally is imperative (Campbell et al., 2001). Similarly, Irvine and Pontiff (2009) reported the increasing of volatility of abnormal returns for U.S. equity return. Thus, it is difficult to expect a constant return on equity in a dynamic market. Cohen et al. (1997) found that inflation, even at its relatively low current rates, continues to increase the cost of capital (required return). In addition, a number of studies strongly rejected the repeated discounting of health effects (Attema, 2012 and Bleichrodt et al. 2016). Feldstein (1983) explained that increasing inflation results in a decreasing discount rate, which in turn leads to an increase in the value of an asset. Turvey et al. (1995) stated that the cost of capital never remains constant because of the changing economy and expressed concern about the assumption of a constant discount rate. Fama and French (1988) explained that time-varying discount rates are consistent with investors' preference for current against future consumption and the stochastic evolution of their investment opportunities.

There is evidence to support the notion that a changing discount rate predicts the market value of equity better than a constant discount rate. Geltner and Mei (1995) found that the explanatory ability of the discounted cash flow model was better under a changing required return than under a constant required return. McLemore et al. (2015) implemented a dividend model using a time-varying discount rate and concluded that it reduced the prediction error when market volatility increased. Attema et al. (2018) argued that after summarizing the theoretical foundations of discounting 
in health care economic evaluations, people should be more cautious about applying equal discounting of costs and effects, particularly when the value of health is expected to change over time. Campbell and Mei (1993) explained that changes in the stock process are due to changes in total required returns rather than to changes in the market's cash flow expectations. Similarly, Hodrock (1992) and Keim and Stambaugh (1986) used interest rate variables to explain that stock returns are predictable. Likewise, Saha and Malkiel (2012) examined and inferred that time-varying discount rates, which are appropriate in valuing U. S start-up firms, were considerably higher than those in traditional discounted cash flow models. Campbell et al. (2018) assumed that variables such as cash flow and discount rate components followed the same volatility dynamics, which govern the conditional variance of market return. Cenesizoglu and Ibrushi (2017) explained that the contribution of discount rate news varies between $24 \%$ and $65 \%$, whereas that of cash flow news varies between $15 \%$ and $61 \%$ and is relatively less volatile. They also explained that components of market return, including cash flow and discount rate news, may also have time-varying conditional variances and covariance. Campbell et al. (2013) explained that positive revisions in return expectations resulted in the downturn of 2001. Moreover, four variables (i.e., industrial product index, producer price index, unemployment rate, and total nonfarm payroll) were found to be important determinants of market return volatility (Engle et al.2013). Ahrendsen and Khoju (1994) rejected the assumption of a constant discount rate. Falk (1991) described that excess volatility in farm asset values may be better explained by time-varying discount rates. Campbell and Mei (1993) reported that changes in stock prices over time happen because of changes in the market's required return, including capital return. Most of the changes in commercial property market value have been due to changes in expected returns or discount rates rather than changes in expected future operating cash flow (Geltner and Mei, 1995). Tiwari (1994) elucidated that opportunity costs may change because of changing economy, and using a single discount rate (estimated either by any of the measures of central tendency or by econometric methods) may not be appropriate as it can overestimate or underestimate the expected market value of equity under variable market rate conditions. Therefore, it is more appropriate to use multiple single-period rates as discounting factors rather than a single rate (Tiwari, 1994).

Today, the market is dynamic because of the presence of globalization, aggressive competition, and the pressure of short-term incentives for senior executives to produce results. In a dynamic market, a constant return on equity or a constant normal market return cannot be expected. Studies have also supported the notion that the required return changes because of changing inflation and a changing economy. Studies conducted on other valuation models indicated that valuation models under a changing required return better explain the market value of equities than a constant required return.

As the existing EVA-based valuation model suggested under the assumption of constant required return cannot be implemented under changing required return, this study first focused on how to implement an EVA-based valuation model under changing required return. Then, it focused on comparing the explanatory ability of the EVA-based valuation model suggested under changing required return with that of the traditional EVA-based valuation model operating under constant required return. 


\section{EVA and EVA valuation model}

\section{Eva}

EVA evaluates financial performance of specific company by comparing (deducting) required earnings with company specific earnings.

The following equation represents the suggested method of finding EVA.

$$
\mathrm{EVA}=\mathrm{NOPAT}-\mathrm{WACC} * \mathrm{TCE}
$$

Where, NOPAT is the net operating profit after interest, WACC is the weighted average cost of capital, and TCE is the total capital employed.

$$
\mathrm{WACC}=\mathrm{I}_{\mathrm{d}} * \mathrm{~W}_{\mathrm{d}}+\mathrm{r}_{\mathrm{e}} * \mathrm{~W}_{\mathrm{e}}
$$

Where $I_{d}$ is the interest on debt capital after tax; $r_{e}$ is the required rate of return; Wd is the weightage of debt capital (debt capital/ TCE); and We is the weightage of equity capital (book value of equity/TCE).

Therefore,

$$
\begin{gathered}
\text { EVA }=\text { NOPAT }-\left(\mathrm{I}_{\mathrm{d}} * \mathrm{~W}_{\mathrm{d}}+\mathrm{r}_{\mathrm{e}} * \mathrm{~W}_{\mathrm{e}}\right) * \mathrm{TCE} \\
=\mathrm{NOPAT}-\left(\mathrm{I}_{\mathrm{d}} * \mathrm{~W}_{\mathrm{d}} * \mathrm{TCE}+\mathrm{r}_{\mathrm{e}} * \mathrm{~W}_{\mathrm{e}} * \mathrm{TCE}\right) \\
=\mathrm{NOPAT}-\left\{\mathrm{I}_{\mathrm{d}} *\left(\mathrm{~W}_{\mathrm{d}} * \mathrm{TCE}\right)+\mathrm{r}_{\mathrm{e}} *\left(\mathrm{~W}_{\mathrm{e}} * \mathrm{TCE}\right)\right\} \\
\mathrm{Wd} * \mathrm{TCE}=\{(\text { debt capital } / \mathrm{TCE}) * \mathrm{TCE}\}=\text { debt capital }
\end{gathered}
$$

In addition, $\mathrm{We}^{*} \mathrm{TCE}=(\mathrm{BVE} / \mathrm{TCE})^{*} \mathrm{TCE}=\mathrm{BVE}$, where $\mathrm{BVE}$ is the book value of equity.

Thus,

$$
\begin{aligned}
& \text { EVA }=\text { NOPAT }-(\mathrm{Id} * \text { debt capital }+\mathrm{re} * \mathrm{BVE}) \\
& =(\mathrm{NOPAT}-\mathrm{Id} * \text { debt capital })-\mathrm{re} * \mathrm{BVE} \\
& =\mathrm{e} \text { PAIT }-\mathrm{re} * \mathrm{BVE} \\
& =\mathrm{r} * \mathrm{BVE}-\mathrm{re} * \mathrm{BVE} \\
& =(\mathrm{r}-\mathrm{re}) * \mathrm{BVE}
\end{aligned}
$$

Where PAIT is the profit after interest and tax, PAIT is $\mathrm{r}^{*}$ book value of equity, and $\mathrm{r}$ is the return on the book value of equity.

\section{EVA-based valuation model}

O'Byrne et al. (1996) clearly indicated that EVA based valuation model had been derived from the addition of current operation value and future growth value.

The equations elaborate the derivation process of EVA based valuation model.

$$
\mathrm{EMVE}=\mathrm{COV}+\mathrm{FGV}
$$

Where COV is the current operational value; FGV is the future growth value; and $\mathrm{COV}$ is the PV of the PAIT expected to be generated by the current invested capital.

In addition, FGV $=\mathrm{PV}$ of $\triangle \mathrm{EVAs}$ generated by future invested capital, where PV is the present value, and $\triangle E V A s$ represent incremental EVAs.

\section{Deriving the EVA-based valuation model under no assumption}

The analysis started with PAIT. After deducting and adding re* BVE to PAIT, PAIT remained unchanged: 
$\mathrm{PAIT}=\mathrm{PAIT}-\mathrm{re} * \mathrm{BVE}+\mathrm{re} * \mathrm{BVE}$

$\mathrm{PAIT}=\mathrm{r} * \mathrm{BVE}$

Thus,

$$
\begin{gathered}
\text { PAIT = r } * \text { BVE }-\mathrm{re} * \mathrm{BVE}+\mathrm{re} * \mathrm{BVE} \\
=(\mathrm{r}-\mathrm{re}) * \mathrm{BVE}+\mathrm{re} * \mathrm{BVE} \\
=\mathrm{EVA}+\mathrm{re} * \mathrm{BE} \\
=\mathrm{re} * \mathrm{BVE}+\mathrm{EVA}
\end{gathered}
$$

If $\mathrm{re}^{*} \mathrm{BVE}=$ required earnings or normal market earnings (NMEs)

Thus, PAIT = NME + EVA, and the PV of PAITs $=$ PV of NMEs + PV of EVAs, where NME and EVA are mutually exclusive, and PAITs are expected to be earned by current invested capital.

In addition, PV of PAITs $=\mathrm{COV}$.

Thus,

$$
\mathrm{COV}=\mathrm{PV} \text { of NMEs }+\mathrm{PV} \text { of EVAs }
$$

Where EVAs and NMEs are expected to be earned by current invested capital.

By adding FGV in Eq. (4), we obtained.

$$
\mathrm{COV}+\mathrm{FGV}=\mathrm{PV} \text { of NMEs }+\mathrm{PV} \text { of EVAs }+\mathrm{PV} \text { of } \triangle \mathrm{EVAs} .
$$

Thus,

$$
\mathrm{EMVE}=\mathrm{PV} \text { of NMEs }+\mathrm{PV} \text { of EVAs }+\mathrm{PV} \text { of } \triangle \mathrm{EVAs}
$$

\section{Deriving EVA-based valuation model under the assumption of constant NMR}

Under the assumption of a constant required return, the PV of NMEs = Perpetual value of NMEs.

$$
\begin{aligned}
& =\mathrm{NME} / \mathrm{re} \\
& =\mathrm{re} * \mathrm{BVE} / \mathrm{re}=\mathrm{BVE}^{.}
\end{aligned}
$$

In addition, the PV of EVAs = perpetual value of current $E V A=E V A / r e$.

Similarly, the PV of $\triangle E V A s=P V$ of $(\triangle E V A s / r e)$.

Thus (O'Byrne et al., 1996),

$$
\mathrm{EMVE}=\mathrm{BVE}+(\mathrm{EVA} / \mathrm{re})+\mathrm{PV} \text { of }(\Delta \mathrm{EVAs} / \mathrm{re})
$$

In standard form, the above equation can be represented as follows:

$$
\begin{aligned}
& \mathrm{EMVE} \text { at the year"t" }=\mathrm{BVE}+\mathrm{EVA} / \mathrm{re}+\sum_{\mathrm{t}=1}^{\infty} \frac{\Delta \mathrm{EVAt} / \mathrm{re}}{(1+\mathrm{re})^{\mathrm{t}}} \\
& \mathrm{EMVE}=\mathrm{BVE}+\mathrm{PV} \text { of EVAs }
\end{aligned}
$$

In standard equation form, the above equation can be written as,

EMVE at the year " $\mathrm{t}$ " $=\mathrm{BVE}+\sum_{t=1}^{\infty} \underline{E V A t}(1+r e)^{t}$

Equations 6 and 7 report that the PV of EVAs generated by all invested capitals is equal to the addition of PV of EVAs generated by the current invested and the PV of $\triangle$ EVAs generated by future invested capital. 
Deriving EVA-based valuation model under the assumption of changing required return Under a changing NMR, the present value of NME remains the same. Therefore,

$$
\mathrm{EMVE}=\mathrm{PV} \text { of } \mathrm{NME}+\mathrm{PV} \text { of EVAs }
$$

In standard form,

$$
\begin{aligned}
& \text { EMVE at the year"t" }=\mathrm{R}_{\mathrm{t}}+\mathrm{R}_{\mathrm{t}+1} /\left\{\left(1+\mathrm{r}_{\mathrm{t}+1}\right)\right\}+\mathrm{R}_{\mathrm{t}+2} /\left\{\left(1+\mathrm{r}_{\mathrm{t}+1}\right) *\left(1+\mathrm{r}_{\mathrm{t}+2}\right)\right\} \\
& +\mathrm{R}_{\mathrm{t}+3} /\left\{\left(1+\mathrm{r}_{\mathrm{t}+1}\right) *\left(1+\mathrm{r}_{\mathrm{t}+2}\right) *\left(1+\mathrm{r}_{\mathrm{t}+3}\right)\right\}+\ldots \ldots+\left\{\mathrm{EVA}_{\mathrm{t}}\right. \\
& +\left[\mathrm{EVA}_{\mathrm{t}+1} /\left\{\left(1+\mathrm{r}_{\mathrm{t}}\right) *\left(1+\mathrm{r}_{\mathrm{t}+1}\right)\right\}\right. \\
& +\mathrm{EVA}_{\mathrm{t}+2} /\left\{\left(1+\mathrm{r}_{\mathrm{t}}\right) *\left(1+\mathrm{r}_{\mathrm{t}+1}\right) *\left(1+\mathrm{r}_{\mathrm{t}+2}\right)\right\} \\
& +\mathrm{EVA}_{\mathrm{t}+3} /\left\{\left(1+\mathrm{r}_{\mathrm{t}}\right) *\left(1+\mathrm{r}_{\mathrm{t}+1}\right) *\left(1+\mathrm{r}_{\mathrm{t}+2}\right) *\left(1+\mathrm{r}_{\mathrm{t}+3}\right)\right\}+\ldots,
\end{aligned}
$$

where $R_{t}, R_{t+1}$, and $R_{t+2}$ are normal market earnings over the years $t, t+1, t+2 ; r$ $t+1, r_{t+2}$, and $r_{t+3}$ are normal market rate of return over the years $t, t+1$, and $t+2$; and $\mathrm{EVA}_{t}, \mathrm{EVA}_{\mathrm{t}+1}$, and $\mathrm{EVA}_{\mathrm{t}+2}$ are the EVAs that generated all the invested capital over the years $t, t+1$, and $t+2$.

\section{Sample and variables}

Sample

For this study, most of the data were collected from the Ace Equity database of Accord Fintech Pvt. Ltd. The database carries more than 15 years of historical financial and share price data from more than 38,000 Indian companies from numbers 10 and up different industries. To examine the explanatory ability of the EVA-based valuation model under both the assumptions, the study used data from 236 companies selected from BSE-500 companies on the basis of the availability of complete information over a 15-year period (2002-2003 to 2016-2017). Out of the 236 companies, 69 were largecap, 88 were mid-cap, and 79 were small-cap companies. The study considered the current year and the following 4 years of actual data to determine the expected market value of equity of the current year to avoid estimation error. Thus, using data over a period of 15 years (2002-2003 to 2016-2017), this study determined the expected market value of equity over a period of 11 years (2002-2003 to 2012-2013). However, the final sample comprised 192 pairs, 235 pairs, and 201 pairs of expected and actual market values of equity for the years 2002-2003, 2007-2008, and 2012-2013 from large-, mid-cap, and small-cap companies, respectively, to reduce autocorrelation and avoid data overlapping.

\section{The variables of EVA valuation models}

The variables used for examining the efficiency of EVA valuation model under constant required return vs. under variable required return are market value of equities and intrinsic value of equities determined by each of the valuation model. The book value of equity and present value of EVAs are the variables required to find intrinsic value of equity using EVA based valuation model under constant required return. Similarly, present value of required earnings and present value of EVAs are the variables required to find intrinsic value of equity using EVA valuation model under changing required return.

The list of following variables were used this study: 
MVE: Average market value of equity.

BVE: Book value of equity

PVRR: Present value of normal market earnings or required earnings

PVEVAUCRR: Present value of EVAs under a constant required rate of return

PVEVAUVRR: Present value of EVAs under a time-varying required rate of return

IVEUCRR: Intrinsic value of equity under a constant required return

IVEVRR: Intrinsic value of equity under a varying required rate of return

\section{Computation of variables}

MVE The average daily trading price of a share for the year multiplied by the number of outstanding shares at the end of the financial year. This information was collected from Ace Equity.

Book value of equity The average book value of equity, determined by adding the opening book value of equity with the closing book value and finally dividing by 2 .

\section{Computation of EVA}

The EVA was computed EVA $=\left(r-r_{e}\right)^{*} B E$, where $r$ is the rate of revenue (accounting) return, and $r_{e}$ is the normal market return.

\section{Computation of normal market rate of return}

The normal market rate of return was computed as $r_{e}=r_{f}+\beta *\left(r_{m}-r_{f}\right)$, where the normal market rate of return was determined by using the CAPM model with variation to match with " $r$ " (rate of return).

Risk-free return $\left(\mathbf{r}_{\mathbf{f}}\right)$ Annualized Treasury bond rates were from the Handbook of Statistics on the Indian Economy of the Reserve Bank of India from 2002 to 2003 through 2016-2017. Additional file 1: Table S1 provides information for finding the risk-free return.

Beta $(\beta)=\operatorname{COV}(\mathrm{r}, \mathrm{re}) / \mathrm{V}(\mathrm{re})$, where COV stands for covariance, and V stands for variance.

\section{Market return with risk $1\left(r_{m}\right)$}

This study considered the revenue return on the book value of the equity of SENSEX as " $r_{m}$ " instead of the annual capital growth rate of SENSEX to find the EVA more accurately. SENSEX stands for the sensitive index, comprising 30 companies.

The average annual earnings price ratios and average annual price book value ratio of the Bombay Stock Exchange Sensitive Index were collected from the Indian Economy of the Reserve Bank of India from 2002 to 2003 through 2016-2017.

Mathematically, $\mathbf{r}_{\mathbf{m}}=$ earnings price ratio* price book value ratio.

Unadjusted risk associated with the equity of a specific company ( $\beta$ factor): Calculated $\beta$ factors were obtained from Ace Equity of Accord Fintech Pvt. Ltd. Similarly, Beta $(\beta)=\operatorname{COV}(\mathrm{r}, \mathrm{re}) / \mathrm{V}$ (re), where "COV" stands for covariance, and "V" stands for variance. 
Computation of varying required rate of return The value was determined by considering the annual average of risk-free return, beta, and market return.

Computation of constant required rate of return It was determined by considering the average of risk-free return, beta, and market return over the entire sample period.

Finding EVAUCRR EVAUCRR $=\left(\mathbf{r}-r_{e}\right.$, i.e., constant over the sample period $) * B V E$

Finding EVAUVRR EVAUVRR $=\left(r-r_{e}\right.$, i.e., changes over the sample period $) * B V E$.

\section{Finding the intrinsic value of equity}

It was assumed that the investors used the expected EVAs, expected required earnings, and terminal value at time " $\mathrm{t}$ " to estimate the intrinsic or expected market value of equity at each time point. The study captured both the effect of expected changes in EVAs and required earnings. The estimated market value of equities was determined using the EVA-based valuation model under the assumption of constant as well as changing required return. To evaluate the performance of the model accurately under each of the assumptions, the study considered actual data instead of predicted data to reduce the error caused by estimation. We followed the procedure used in studies conducted by Foerster \& Sapp (2005); Steiger (2010); and McLemore et al. (2015).

We also considered the existing data while assuming that investors expected what they were receiving. The process of finding the expected market value under each assumption involved three different stages. In the first stage, we found the present value of EVAs and the present value of the required earnings by considering the actual EVAs of the current year and the following 4 years as determined under each of the assumptions (constant and changing normal market return). We also found the required earnings of the current year and the following 4 years. In the second stage, the terminal values of the required earnings and EVAs under each of the assumptions were determined using Gordon's growth model. We first found the average of the current and future 4 years' required earnings and EVAs. The average of 5 years' EVAs and required earnings were multiplied with the one-plus growth rate, and the result was divided by normal market return minus the growth rate. Finally, the present value of required earnings (normal market earnings), the present value of EVAs computed under changing required return in stage 1 , the terminal value of the normal market earnings, and the terminal value of EVAs under a changing required rate of return (as computed in stage 2) were added up to obtain the expected market value of equity by the EVA-based valuation model under the changing required return. Similarly, the present value of EVAs determined under constant required return in stage 1, the terminal value of EVAs determined under constant required return in stage 2 , and the book value of equity were added up to get the expected market value of equity under constant required return.

\section{Determining the intrinsic value of equity using the EVA-based valuation model constant required return}

EVA valuation model determines intrinsic value of equity by adding average book value of equity, discounted value of 5 years' of EVAs and present value of terminal value of EVA under constant required return . 
EMVE (expected market value of equity) of year $\mathrm{t}=\mathrm{BVE}+\sum_{\mathrm{t}=1}^{5} \mathrm{EVAt} /(1+\mathrm{c})^{\mathrm{t}-1}+$ present value of the terminal value of EVA, which was the average of last 5 years' EVAs.

\section{Determining intrinsic value of equity using EVA-based valuation model under changing required return}

EVA valuation model under changing required return determines intrinsic value of equity by adding discounted value of required earnings with discounted value of EVAs under changing required earnings. Therefore, we have added discounted value of 5 years' required earnings, includes current year's required earning and following 4 years' required earnings, with terminal value of required earnings to find discounted value of required earnings. Similarly, we have added discounted value of 5 years' EVAs, includes current year and following 4 years' EVAs, with terminal value of EVA determined under changing required return to find expected market value of equity. EMVE of year "t" $=\mathrm{R}_{\mathrm{t}}+\mathrm{R}_{\mathrm{t}+1} /\left(1+\mathrm{r}_{\mathrm{t}+1}\right)+\mathrm{R}_{\mathrm{t}+3} /\left\{\left(1+\mathrm{r}_{\mathrm{t}+1}\right)\left(1+\mathrm{r}_{\mathrm{t}+2}\right)\left(1+\mathrm{r}_{\mathrm{t}+3}\right)\right\}+\mathrm{R}_{\mathrm{t}+4} /\left\{\left(1+\mathrm{r}_{\mathrm{t}}\right.\right.$ 1) $\left.\left(1+r_{t+2}\right)\left(1+r_{t+3}\right)\left(1+r_{t+4}\right)\right\}+P V$ of (Terminal Value of expected required earnings after year five, which was the average of the last 5 years' NME $)+E^{\prime} A_{t}+E A_{t+1} /(1+$ $\left.r_{t+1}\right)+E A_{t+3} /\left\{\left(1+r_{t+1}\right) \quad\left(1+r_{t+2}\right)\left(1+r_{t+3}\right)\right\}+E A_{t+4} /\left\{\left(1+r_{t+1}\right) \quad\left(1+r_{t+2}\right)\left(1+r_{t+3}\right)\right.$ $\left.\left(1+r_{t+4}\right)\right\}+$ PV of (Terminal Value of expected EVAs after year five, which was the average of the last 5 years' EVAs).

\section{Hypotheses}

\section{Statement of hypotheses}

Our hypotheses were as follows:

H1: The explanatory ability of the EVA-based valuation model is better under the assumption of constant required return than under the scenario of changing required return.

$\mathrm{H} 2$ : The explanatory ability of the EVA-based valuation model is not better under the assumption of constant required return than under the scenario of changing required return.

We intended to reject the first hypothesis if the explanatory ability of EVA based valuation model under constant required return is less than the explanatory ability of EVA based valuation under changing required return. This enabled us to accept the second hypothesis. Reported $\mathrm{R}$ and $\mathrm{R}^{2}$ values between market value of equity and expected market value of equity determined by each of the valuation models determines the explanatory ability of each of the valuation models.

The regression model specification for examining the relative information content of the valuation model

In order to examine the hypotheses, the first equation below was used to find the regression relationship between the expected market value of equities determined by the EVA valuation model under the assumption of a constant required return and an average actual market value of equities of "i" company over time "t," whereas the second equation was used to determine the regression relationship between the expected market value of equities determined by the EVA valuation model under the condition of a 
changing required return and the average actual market value of equities. To effectively and accurately determine the regression relationship under each of the assumptions, we conducted linearity, homoscedasticity, and auto-correlation tests. A log transformation process is also carried out to maintain a model fit.

$$
\begin{aligned}
& \text { MVE }_{i t}=\mathrm{t}_{0}+\mathrm{t}_{1} * \text { IVEVAUCRR }+\mathrm{e}_{\mathrm{it}} \\
& \text { MVE it }=\mathrm{w}_{0}+\mathrm{w}_{1} * \text { IVEVAUVRR }+\mathrm{e}_{\mathrm{it}}
\end{aligned}
$$

\section{Results and discussion}

\section{Relative regression analysis across the years}

To explore whether the association of the intrinsic value of equities determined by the EVA-based valuation model under the assumption of a constant required return with a market value of equities is better than that determined by the EVA-based valuation model under the assumption of changing required return, we conducted a regression analysis that is reported in Table 1 . The table presents the results of the regression analyses conducted on the cross-sectional positive expected market value of equities (independent variables) determined by using the EVA valuation model under each of the conditions (constant and variable required return) and market value of equities (dependent variables) selected from large, mid-, and small-cap companies. To reduce autocorrelation and avoid data overlapping, the study comprised the calculated and actual market value of equity every fifth year, including the years 2002-2003, 2007-2008, and 2012-2013. The final samples were selected with the condition of positive intrinsic values. Panels A, B, and C (Table 1) represent the overall results of the large-cap, midcap, and small-cap companies, respectively, across the years. We selected 192 positive expected and actual market values of equities of 69 large-cap companies determined under each of the assumptions, 235 positive expected and actual market values of equities of 88 mid-cap companies determined under each assumption, and 201 positive expected and actual market values of equities of 79 small-cap companies determined under each of the assumptions. In large-cap companies, Durbin-Watson's number indicated the absence of autocorrelation as it lays within the limit of 1.5 and 2. Moreover, the F-values, 603.12 and 350.627, and the $p$-values indicated that the intrinsic values determined by the EVA valuation model under both the assumptions maintained a significant association with the actual market value of equities. We also observed that the

Table 1 Overall Results across the Years

\begin{tabular}{lllllll}
\hline Models & $\mathrm{R}$ & $\mathrm{R}^{2}$ & Adjusted $\mathrm{R}^{2}$ & F value & D-W & Sig. \\
\hline Large cap & & & & & & \\
EVME UVRR & 0.872 & 0.760 & 0.759 & 603.120 & 1.633 & 0.000 \\
EVME UCRR & 0.805 & 0.649 & 0.647 & 350.627 & 1.632 & 0.000 \\
Mid Cap Company & & & & & & \\
EVEUVRR & 0.812 & 0.660 & 0.659 & 452.290 & 1.993 & 0.000 \\
EVEUCRR & 0.691 & 0.477 & 0.475 & 212.794 & 2.080 & 0.000 \\
Small Cap Company & & & & & & \\
EMVEUVRR & 0.730 & 0.533 & 0.531 & 227.028 & 2.172 & 0.000 \\
EMVEUCRR & 0.378 & 0.143 & 0.139 & 77.037 & 1.947 & 0.000 \\
\hline
\end{tabular}


correlation coefficient of the intrinsic or expected market value of the equities determined by the EVA-based valuation model under the assumption of constant required return (87.2\%) was lower than the correlation coefficient of the intrinsic value determined by the EVA-based valuation model under the assumption of changing required return (80.5\%). Furthermore, the intrinsic value of equities determined by the EVAbased valuation model under the assumption of constant required return for large-cap companies explained a $64.7 \%$ variance in its actual average market value of equities. In contrast, the intrinsic value of the equities determined by the EVA-based valuation model under the assumption of changing required return explained $75.9 \%$ variance in the actual market value of equities. Thus, the explanatory ability of the EVA-based valuation model under a changing required return was $11.2 \%$ higher than the explanatory ability of the valuation model under the assumption of constant required return.

For mid-cap companies, Durbin-Watson's number indicated the absence of autocorrelation, as it remained closer to or within the upper and lower limits of 1.5 and 2. In addition, the F-values, 452.290 and 212.794, and the $p$-value, 0.000 , indicated that the association of intrinsic values of equities determined by the EVA-based valuation model under the assumption of a constant and changing required return with the market value of equities was significant, at less than 0.001 . Furthermore, as panel B in Table 1 indicates, the intrinsic values of equities determined by the EVA-based valuation model under both the assumptions were positively correlated with the market value of equities. The expected/intrinsic value of equities determined by the EVA-based valuation model under the assumption of a changing required return explained the $65.9 \%$ variation in the actual market value of equity. In contrast, the intrinsic value of equities determined by the EVA-based valuation model under a constant required return explained the $47.5 \%$ variance in the market value of equities. Thus, the explanatory ability of the EVA-based valuation model under the assumption of a changing required return was $18.4 \%$ higher than that of the model under a constant required return.

In small-cap companies, Durbin-Watson's number indicated the lower-level presence of autocorrelation. The F-values, 227.028 and 77.037, and the $p$-value, 0.000, signaled the significance of the association of the intrinsic value of equities determined using the EVA valuation model under the assumption of constant and changing required return at less than 0.001 . Moreover, the expected market value of the equity determined under changing required return explained the $53.3 \%$ variation in the actual market value of equity. In contrast, the expected market value of equities determined by the valuation model under constant required return explained the $14.3 \%$ variation in the actual market value of equity. Thus, the explanatory ability of the EVA-based valuation model under the assumption of changing required return was $6.2 \%$ higher than that of the EVA-based valuation model under the assumption of constant required return.

The above result rejected Hypothesis 1, as Pearson's correlation and the coefficient of determination between the expected market value of equities determined by the EVA valuation model under the assumption of constant required return and the market value of equities remained lower than that between the expected market value of equities determined by the EVA valuation model under the scenario of changing required return and market value of equities. It indicates that explanatory ability of EVA based valuation model under changing required return is better than the explanatory ability of EVA based valuation model under 
constant required return. Thus, we accepted hypothesis 2 and proved the validity of hypothesis 2 .

Table 1: Results of regression analysis conducted on 69 large-cap, 88-mid cap, and 79 small-cap companies considering 192 samples of the expected market value of equities, 235 samples of the expected market value of equity variables, and 201 samples of the expected market value of equities determined by the EVA-based valuation model under each of the assumptions along with market value of equities of respective companies over the period of 2002-2003 through 2016-2017. EVME UVRR represents the expected market value of equities under variable required return, EVMEUCRR represents the expected market value of equities under constant required return, and EMVEUVRR stands for the expected market value of equities.

\section{Relative analysis over the years}

Table 2 shows the results of regression analyses conducted on selected samples (independent and dependent variables) of large-cap, mid-cap, and small-cap companies on a yearly basis. The independent variables represent the expected market value of equities determined by the EVA valuation model under the assumption of a constant required return. Table 3 presents the results of regression analysis conducted between the market value of equities and the expected market value of equities determined under the assumption of a changing required return. In both the tables, samples of large-cap companies comprised 60 independent and dependent variables for 2013, 68 independent and dependent variables determined for 2008, and 67 independent variable and dependent variables for 2003. Samples of mid-cap companies included 72 independent and dependent variables for 2013, 84 independent and dependent variables for 2008, and 78 independent and dependent variables for 2003. Samples of small-cap companies included 67 independent and dependent variables for 2013, 70 independent and dependent variables for 2008, and 79 independent and dependent variables for 2003.

Table 2 EVA Valuation Model under Constant Required Return

\begin{tabular}{cllllll}
\hline & $R$ & $R^{2}$ & Adjusted $R^{2}$ & F-Value & D-W & Sig. \\
\hline Large Cap & & & & & & \\
2013 & 0.754 & 0.568 & 0.561 & 76.404 & 1.546 & 0.000 \\
2008 & 0.713 & 0.508 & 0.501 & 68.262 & 1.426 & 0.000 \\
2003 & 0.882 & 0.778 & 0.775 & 217.81 & 1.741 & 0.000 \\
Mid Cap & & & & & & \\
2013 & 0.471 & 0.228 & 0.217 & 20.723 & 1.559 & 0.000 \\
2008 & 0.651 & 0.424 & 0.417 & 60.390 & 1.816 & 0.000 \\
2003 & 0.832 & 0.692 & 0.688 & 170.89 & 1.626 & 0.000 \\
Small Cap & & & & & & \\
2013 & 0.429 & 0.184 & 0.171 & 14.645 & 2.139 & 0.000 \\
2008 & 0.521 & 0.272 & 0.261 & 25.36 & 1.94 & 0.000 \\
2003 & 0.693 & 0.48 & 0.472 & 60.97 & 2.12 & 0.000 \\
\hline
\end{tabular}

Note: Table 3 reports the result of regression analysis between market value of equities and expected market value of equities of large cap, mid cap, and small cap companies determined by EVA based valuation model with a varying required return 
Table 3 EVA Valuation Model under Changing Required Return

\begin{tabular}{cllllll}
\hline & $R$ & $R^{2}$ & AdjustedR $^{2}$ & F-Value & D-W & Sig. \\
\hline Large Cap & & & & & & \\
2013 & 0.875 & 0.765 & 0.761 & 188.625 & 2.24 & 0.000 \\
2008 & 0.739 & 0.547 & 0.540 & 79.539 & 1.50 & 0.000 \\
2003 & 0.890 & 0.792 & 0.789 & 236.388 & 1.994 & 0.000 \\
Mid Cap & & & & & \\
2013 & 0.699 & 0.489 & 0.482 & 67.879 & 1.735 & 0.000 \\
2008 & 0.738 & 0.544 & 0.539 & 97.88 & 1.775 & 0.000 \\
2003 & 0.843 & 0.711 & 0.707 & 187.13 & 1.616 & 0.000 \\
Small Cap & & & & & & \\
2013 & 0.589 & 0.347 & 0.337 & 34.53 & 2.17 & 0.000 \\
2008 & 0.592 & 0.35 & 0.341 & 36.67 & 1.986 & 0.000 \\
2003 & 0.683 & 0.467 & 0.459 & 57.839 & 2.01 & 0.000 \\
\hline
\end{tabular}

Note: Table 3 reports the result of regression analysis between market value of equities and expected market value of equities of large cap, mid cap, and small cap companies determined by EVA based valuation model with a varying required return

In Table 3, Durbin and Watson's (D-W) numbers for large and mid-cap companies indicated little or no presence of autocorrelation within the samples, whereas for smallcap companies, the D-W number indicated the presence of little autocorrelation within the sample data. In addition, the F-values and the $p$-value of all large-cap, mid-cap, and small-cap companies (Table 2) indicated that all the expected market values of equities for all the companies were significant, at less than 0.001. As Table 3 shows, the D-W numbers of the large- and mid-cap companies for 2003, 2008, and 2013 indicated a virtual absence of autocorrelation, whereas the $\mathrm{D}-\mathrm{W}$ number indicated a milder presence of autocorrelation with the sample data of small-cap companies. The F-values and $p$ values indicated that the expected market value of the equities of large-, mid-, and small-cap companies, as determined by the valuation model with the assumption of varying required return, was significantly associated with the market value of equities. Moreover, the expected market value of the equities of large-cap companies in 2013, as determined under the assumption of a changing required return, explained why there was $20 \%(76.1 \%$ vs. $56.1 \%)$ more variance in the market value of equities compared to the expected market value of equities as explained under the assumption of a constant required return. During 2008, the expected market value of equities as determined under a changing required return explained why there was $3.9 \%$ (54\% vs.50.1\%) more variance in the market value of equities compared to the expected market value of equities as explained under a constant required return. In 2003, the expected market value of equities as determined by the valuation model under a changing required return explained the $1.4 \%$ ( $78.9 \%$ vs. $77.5 \%)$ higher variance compared to the expected market value of equities as explained the under constant required return. Moreover, the expected market value of the equities of mid-cap companies in 2013, as determined under the assumption of a changing required return, explained the $26.5 \%$ (48.2\% vs. 21.7\%) higher variance of the market value of equities compared to the expected market value of equities explained under the assumption of a constant required return. In 2008, the expected market value of the equities determined under a changing required return explained the $12.2 \%$ (53.9\% vs.41.7\%) higher variance in the market value of 
equities compared to the expected market value of equities as explained under a constant required return. In 2003, the expected market value of equities determined by the valuation model under a changing required return explained the $1.9 \%$ (70.7\% vs. $68.8 \%)$ higher variance compared to the expected market value of equities explained under a constant required return. Moreover, the expected market value of equities of small cap companies during 2013 determined under the assumption of changing the required return explained the $16.6 \%$ (33.7\% vs. $17.1 \%$ ) higher variance in the market value of equities compared to the expected market value of equities explained under the assumption of constant required return. Similarly, in 2008, the expected market value of equities determined under the changing required return explained the $8 \%(34.1 \%$ vs. $26.1 \%)$ higher variance in the market value of the equities compared to the expected market value of equities explained under a constant required return.

The above results led us to reject hypothesis 1 . Pearson's correlation and the coefficient of determination between the expected market value of equities determined by the EVA valuation model under the assumption of constant required and market value of equities remained lower than Pearson's correlation and the coefficient of determination between the expected market value of equities determined by the EVA valuation model under the scenario of changing required and market value of equities. Thus, we accepted hypothesis 2 .

In 2003, the expected market value of equities determined by the valuation model under a constant required return explained the $1.3 \%$ ( $45.9 \%$ vs. $47.2 \%)$ higher variance compared to the expected market value of equities explained under changing required return. The result led us to accept hypothesis 1 . This was because Pearson's correlation and the coefficient of determination between the expected market value of equities determined by the EVA valuation model under the assumption of constant required return and market value of equities were higher than those between the expected market value of equities determined by the EVA valuation model under the scenario of changing required return and market value of equities.

\section{Discussion}

The EVA-based valuation model can be used to determine the expected market value of equity by adding the book value of equity with the present value of EVAs under the assumption of constant required return and constant return on equity (Stewart, 1991). Despite a huge body of literature that supports the notion that EVA maintains a strong association with upward and downward trends in stock price, little research has been conducted on the suggested EVA-based valuation model. However, the assumption of constant required return and constant return on equity raise the question whether required rate of return and the return on equity remain constant? A large number of studies have elucidated that the required rate of return does not remain constant. In today's highly dynamic market (hypercompetitive), achieving and sustaining competitive advantage is difficult (D'Aveni, 1994). Additionally, in dynamic markets, dynamic capabilities are necessary to survive (D'Aveni et al., 2010). Thus, the scenario of hyper competition increases the volatility of return, making it difficult to expect a constant required rate of return and a constant return on invested equity capital. Moreover, the EVA valuation model formulated under the assumption of a constant required return cannot be implemented under the real scenario of a changing required return. 
EVA maintains its uniqueness because it considers the cost of capital. Its popularity has increased in countries such as India, where companies including Infosys Technologies, BPL, HUL, NIIT, TCS, Godrej Consumers Product Limited, Ranbaxy Laboratories Ltd., and Samtel India Limited have reported EVA in their financial statements. Researchers in India, such as Behera (2019), Altaf (2016), Pattanayak (2009), Ramadan (2016), Poornima et al. (2015), and Sharma and Kumar (2010), have taken interest in conducting studies on EVA.

The existing uniqueness of EVA and the growing popularity of EVA in India encourage us to focus our study on the EVA-based valuation model. In spite of many success stories of EVA adoption, the suggested valuation model cannot be implemented under the current scenario of changing required return. Therefore, we made an attempt to implement the EVA valuation model under the scenario of changing required return. We first attempted to replace the book value of equity of the existing EVA valuation model with the present value of normal market earnings (as normal market earnings are the multiplication of the normal market return with the book value of equity). We kept other part of the model the same as the present value of EVAs; the valuation model can be implemented under changing required return. Finally, this study compared the explanatory ability of the revised EVA-based valuation model under a changing required return with the explanatory ability of the existing EVA-based valuation model under a constant required return by conducting relative information content analyses over the years. The relative analyses conducted over the years indicated that the explanatory ability of EVA valuation model is better under a varying required return than under constant required return. This was because the EVA-based valuation model under changing required return explained the $75.9 \%, 65.9 \%$, and $53.1 \%$ variance in the market value of equity for large-, mid-, and small-cap companies, and the EVAbased valuation model under constant required return explained the $64.7 \%, 47.5 \%$, and $13.9 \%$ variance in the market value of the equity of large-, mid-, and small-cap companies, respectively. Therefore, we rejected hypothesis 1 and accepted hypothesis 2. Furthermore, the results of the relative information content analyses conducted along the years indicated that explanatory ability of the EVA valuation model under the assumption of changing required return is much better than that under the assumption of constant required return for 2013 and 2008. In contrast, the explanatory ability of the valuation model under the scenario of changing required return remained closer to the explanatory ability of the valuation model under a constant required return for 2003. In addition, the explanatory ability of EVA-based valuation under changing required return was much higher in 2013 compared to the explanatory ability of the EVA-based valuation model under a constant required return; it maintained the largest gap between two models across all categories of companies $(76.1 \%$ vs. $56.1 \%$ for large cap, $48.2 \%$ vs. $21.7 \%$ for mid cap, and $33.7 \%$ vs. $17.1 \%$ for small cap). The gap between two models was reduced for all categories of companies in 2008. Similarly, in 2003, the explanatory abilities of the two models were close to each other and maintained the smallest gap. It must be noted that to compute the intrinsic value for 2013, we used input data up to 2017, as we wanted to consider the following 4 years' data to find the intrinsic value of each year. This result showed that the revised EVA valuation model responded better to the recent market than to the older market. The revised EVAbased valuation model further clarifies that the present value of EVAs determined the 
EVA by deducting the normal market value of equity from the actual market value of equity. This was because EVA can be used to determine economic profit over a specific period by deducting the normal market earnings or required earnings from companyspecific earnings. The normal market value of equity is determined by the present value of normal market earnings. Moreover, EVA valuation model proposed with the assumption of changing required return can be implemented with the assumption of constant required return.

\section{Conclusions}

In this study, the first attempt was made to implement an EVA-based valuation model under the condition of a changing required return and to compare its explanatory ability with the existing EVA-based valuation model under a constant required return.

First, we posited that the EVA-based valuation model could be implemented under the scenario of changing required return by adding the present value of the required earnings with the present value of EVAs. Relative information content analyses were conducted over the years to examine whether the explanatory ability of the revised EVA-based valuation model under changing required return is better than that of the existing EVA-based valuation model suggested under constant required rate of return. The study was conducted over the years on large-, mid-, and small-cap companies. It showed that the EVA-based valuation model explained the $75.9 \%, 65.9 \%$, and $53.1 \%$ variance in the market value of equities. In contrast, the EVA-based valuation model under constant required return explained the $64.7 \%, 47.5 \%$, and $13.9 \%$ variance in the market value of equities. This indicated that the explanatory ability of the EVA-based valuation model under changing required return is much better than the explanatory ability of the EVA-based valuation model under a constant required return. Furthermore, the study conducted over 2003, 2008, and 2013 showed that the explanatory ability of the EVA valuation model under a changing required return was the best in 2013, as it maintained the highest gap $(76.1 \%$ vs. $56.1 \%$ for large-cap, $48.2 \%$ vs. $21.7 \%$ for mid-cap, and $33.7 \%$ vs. $17.1 \%$ for small-cap companies) in 2008 and was marginally higher or lower during 2003. This showed that the superiority of the explanatory ability of EVA-based valuation model increased from 2003 to 2013 and showed that the EVAbased valuation model under changing required return better responded to recent data than to older data. It must be noted that the study considered the input data of the following 4 years i.e., up to 2017 to determine the intrinsic value in 2013. Therefore, the performance of the valuation model in other applications depends upon the timing of dataset in use. The more recent the data, the better the performance of the EVA-based valuation under a changing required return. However, more study is required to confirm this fact.

EVA can be used to determine economic profit by subtracting the normal market earnings from company-specific earnings. Consistent with this idea, the formula of the EVA-based valuation model under changing required return indicates that the present value of EVAs determines EVA by subtracting the normal market value of equity from the market value of equity, where the normal market value of equity is the present value of normal market earnings. Thus, the present value of EVAs measures economic value added over the years, whereas EVA measures economic profit over a specific period. In the process, the suggested equation of the revised EVA-based valuation 
model under changing required return maintained consistency with the core objective of EVA. Moreover, the EVA-based valuation model can be implemented under the assumption of changing as well as a constant required return.

The results of this study supported the findings of researchers such as Hodrock (1992); Keim and Stambaugh (1986); Saha and Malkiel (2012); Geltner and Mei (1995) that asset values are better explained by the time-varying discount rate than constant discount rate. This was true even though the studies were conducted on different valuation models. However, this study supported the statement that the model is not fixed and cannot be used in all circumstances; rather, a different model needs to be set to test various data under the proposed framework, (Chao et al. 2019). This study widened the application of the EVA-based valuation model. It can serve as a guide for investors and corporate managers in the process of selecting a valuation model and for academicians in pursuing further research. It also adds to and strengthens the existing body of literature on the EVA-based valuation model.

\section{Limitations and direction of future research}

For this study, the companies we selected comprised large-, mid-, and small-cap companies listed in the BSE 500. The number of companies was limited because they were selected on the basis of availability of complete data over the period from 2003 through 2017. The number of samples also varied over 2003, 2008, and 2013, as the study considered only the positive estimated market value of equities determined by the EVA valuation model under each of the assumptions. All the data were collected from Ace Equity, which was a secondary source.

This study widened the application of the EVA-based valuation model under the changing required return and compared the efficiency of the revised valuation model under a changing required return with the existing EVA-based valuation model under a constant required return. The results indicated that the EVA-based valuation model under a changing required return performs better than the existing EVA-based valuation model under a constant required return and performs best with recent versus older sample data. The attempt to use the EVA-based valuation model under a changing required return, and the results of this study, opened up a new avenue for researchers to conduct further study.

\section{Supplementary information}

Supplementary information accompanies this paper at https://doi.org/10.1186/s40854-019-0167-8.

Additional file 1: Table S1. (XLS $53 \mathrm{~kb})$

\footnotetext{
Abbreviations

BVE: Book value of equity; COV: Covariance; EMVE: Expected market value of equity; EVA: Economic value added; EVAUCRR: EVA under a constant required return; EVAUVRR: EVA under a varying required return; IVEUCRR: Intrinsic value of equity determined by EVA valuation model under a constant required return; IVEUVRR: Intrinsic value of equity determined by EVA valuation model under a varying required return; MVE: Market value of equity; NOPAT: Net operating profit after tax; PV EVAUVRR: Present value of EVAs under a varying required return; PVEVAUCRR: Present value of EVAs under a constant required return; PVNME: Present value of normal market earnings; PVNME: Present value of normal market earnings; $r$ : Rate of return on equity; $r_{e}$ : Normal market rate of return or required rate of return; V: Variance
} 
Authors' contributions

Ms. Sujata Behera is the sole author of the manuscript. She has conceptualized the idea, conducted the study, and written the manuscript.The author read and approved the final manuscript.

Author's information

Ms. Sujata Behera, Ph.D. Research Scholar, Institute of Management, Nirma University, S.G. Highway, Ahmedabad 382,424 Gujarat, India

\section{Funding}

No specific financial support was received to carry out the study.

\section{Availability of data and materials}

Data are available from the author on reasonable request.

\section{Competing interests}

The author declare that he or she has no competing interests.

Received: 5 November 2018 Accepted: 15 December 2019

Published online: 05 February 2020

\section{References}

Ahmed H (2015) Impact of Firms Earnings and Economic Value Added on the Market Share Value: An Empirical Study on the Islamic Banks in Bangladesh. Global J Manage Bus Res 15(2-D)

Ahrendsen BL, Khoju MR (1994) Constant discount rate and Co-integration analysis of Arkansas farmland prices. It has been presented in the American agricultural economics association meeting. San Diego, California

Altaf N (2016) Economic value added OR earnings: what explains market value in Indian firms? Future Bus J 2:152-166

Ang A and Liu J (2003) How to discount cash flows with time-varying expected returns (October 2003). NBER working paper no. w10042. Available at SSRN: https://ssrn.com/abstract $=461363$

Anderson AM, Weaver SC and Bey RP (2004) Economic Value Added Adjustments: Much to Do about Nothing. A Paper Presented at the Midwest Finance Association Meetings.

Attema AE (2012) Developments in time preference and their implications for medical decision making. J Oper Res Soc 63: $1388-1399$

Attema AE, Brouwer WBF, Claxton K (2018) Discounting in economic evaluations. Pharmacoeconomics 36:745-758. https:// doi.org/10.1007/s40273-018-0672-z

Azamhuzjaev M, Mackey J (2001) Economic Value Added: A Critical Analysis. The Journal of Corporate Accounting and Finance 12(2):65-71

Banerjee A (2000) Linkage between economic value added and market value: an analysis. Vikalpa 25(3):23-36

Behera S (2019) EVA as periodic performance measure for Indian companies. Int I Sci Res Rev 8(2):1-15

Bhasin ML (2013) Economic value added AND shareholders' wealth creation: the portrait of a developing Asian country. Int J Manag Financ Account 5(2):107-137

Biddle GC, Bowen RM, Wallace JS (1997) Does EVA ${ }^{\oplus}$ beat earnings? Evidence on associations with stock returns and firm values. J Account Econ 24:301-336

Bleichrodt H, Gao Y, Rohde KIM (2016) A measurement of decreasing impaitience for health and money. J Risk Uncertain 52: 213-231

Campbell J, Mei J (1993) Where do betas come from?-asset Price Dynamica and the sources of systematic risk. Rev Financ Stud 6:567-592

Campbell JY, Lettau M, Malkiel BG \& XU Y (2001) Have Individual Stocks Become More Volatile? An Empirical Exploration of Idiosyncratic Risk. The Journal of Finance, 1: 1-43.

Campbell JY, Giglio S, Polk C (2013) Hard times. Rev Asset Pric Stud 3:95-132

Campbell JY, Giglio S, Polk C, Turley R (2018) An intertemporal CAPM with stochastic volatility. J Financ Econ 128:207-233

Cates DC (1997) Performance Measrement: welcome to the revolution. Bank Strateg 73:51-56

Cenesizoglu T, Ibrushi D (2017) Time variation in cash flows and discount rates. SSRN: https://ssrn.com/abstract=2943478 or https://doi.org/10.2139/ssrn.2943478

Chamberlain K, Campbell R (1995) Creating shareholder value. N Z Manuf 100:2-15

Chao X, Kou G, Peng Y (2019) Behavior monitoring methods for trade-based money laundering integrating macro and micro prudential regulation: a case from China. Technological and economic development of economy, ISSN: 2029-4913/Eissn: 2029-4921. https://doi.org/10.3846/tede.2019.9383

Chen S, Dodd JL (1997) Economic Value Added (EVA\&\#x2122;): An Empirical Examination Of A New Corporate Performance Measure. J Manag Issues 9:318-333

Cochrane HJ (2011) Presidential address: discount rates. J Finance LXVI 4

Cohen D, Hassett K, Hubbard G (1997) Inflation and user cost of capital: does inflation still matter. The National Bureau of Economic Research

Comin DA, Mulani S (2006) Diverging in aggregate and firm volatility. Rev Econ Stat 88(2):374-383

Comin DA, Philippon T (2005) The Rise in Firm Level Volatility: Causes and Consequences. In: In NBR Macroeconomics Annual

D'Aveni AR (1994) Hypercompetition: managing the dynamics of strategic maneuvering. Free Press, New York

D'Aveni AR, Dagnino BG, Smith GK (2010) The age of temporary advantage. Strateg Manag J 31:1371-1385. https://doi.org/ 10.1002/smj.897

Ehrbar A (1998) Economic Value Added: The Real Key to Creating Wealth. John Wiley and Sons, Inc., New York

Ellanti M (2016) Selected Indian pharmaceutical companies performance through EVA, a study. Int J Sci Technol Manag 5(05): 284-292

Engle RF, Ghysels E, Sohn B (2013) Stock market volatility and macroeconomic fundamentals. Rev Econ Stat 95:776-797 
Ethiraj G (1998) The EVA feather in the market cap. Econ Times 145

Falk B (1991) Formally testing the present value model of farmland prices. Am J Agric Econ 73:1-10

Fama EF, French KR (1988) Permanent and temporary components of stock prices. J Polit Econ 96:246-273

Feldstein M (1983) Inflation and stock market. URL:http://www.nber.org/chapters/c11335, 186-198

Foerster SR, Sapp SG (2005) Dividend Discount Model in the Long-Run: A clinical Study. Journal of Applied Finance 15(2): $1-40$

Geltner D, Mei J (1995) The present value model with time-varying discount rates: Inmplications for commercial property valuation and investement decisions. J Real Estate Financ Econ 11(2):119-135

Gounder CG, Venkateshwarlu M (2017) Shareholder Value Creation: An Empirical Analysis of Indian Banking Sector. Accounting and Finance Research 6(1):148-157

Hodrock R (1992) Dividend Yeilds and expected stock returns: alternative procedures for inference and measurement. Rev Financ Stud 5:357-386

Irvine PJ, Pontiff J (2009) Idiosyncratic Return Volatility, Cash Flows, and Product Market Competition. The Review of Financial Studies 22(3):1149-1177

Keim DB, Stambaugh RF (1986) Predicting returns in the stock and bond markets. J Financ Econ 17:357-390

Khan UA, Aleemi AR, Qureshi MA (2016) Is economic value added more associated with stock Price than accounting earnings: evidence from Pakistan. City Univ Res J 6(2):204-216

Kukreja BK, Giridhar BS (2005) Value- based Peroformance metrics in the pharmaceutical industry. SCMS I Indian Manag 2(1):55-63

Kumar S, Sharma A (2011) Association of EVA and Accounting earnings with market value: evidence from India. Asia Pacific J Bus Adm 3:83-96

Lefkowitz SD (1999) The correlation between EVA and MVA companies. MBA Dissertation, Califernia State University

Lehn K, Makhija AK (1997) EVA, accounting profits, and CEO turnover: an empirical examination, 1985-1994. J Appl Corp Financ 10(2):90-97

Mangala D, Joura S (2002) Linkage between economic value added and market value: an analysis in India context. Indian Manag Stud 6:55-65

McLemore P, Woodward G, Zwirlein T (2015) Back-tests of the dividend discount model using time-varying cost of capital. J Appl Finance (Formerly Financial Practice and Education) 25:2

Mei J, Lee A (1994) Is there a real estate risk factor premium? J Real Estate Financ Econ 8:115-135

Misra A, Kanwal A (2007) Linkage between Economic Value Added and Share Prices: An Empirical Study of Indian Corporate Sector. ICFAl University of Journal of Industrial Economics 11(4):30-37

O'Byrne FS, Stewart S, Co. (1996) EVA and Market value. J Appl Corp Financ 9(1):116-125

Pattanayak JK (2009) An integration of economic value added and balanced scorecard concepts for effective strategic management. In: Deep and deep publications, pp 29-50

Peterson PP, Peterson DR (1996) Company performance and measures of value added. The Research Foundation of the institute of chartered financial analysts. Charlottesville, VA

Poornima BG, Narayan P, Reddy YV (2015) Economic value-added as an emerging tool of performance measurement: evidence from Indian companies. IUP J Account Res Aud Pract 14(3):38

Ramadan IZ (2016) EVA and the impact of the macroeconomic variables: evidence from the Jordanian manufacturing companies. Asian J Finance Account 8(1):13-22

Ramana DV (2005) Market value added and economic value added: empirical evidence from Indian market, Xavier Institute of management, Bhubaneswar 1-15

Saha A, Malkiel BG (2012) Valuation of cash flows with time-varying cessation risk. J Bus Valuation Econ Anal 7(1):1-22. https://doi.org/10.1515/1932-9156.1126

Saxena P (1998) Economic Value Added and Performance Evaluation, The Management Accountant, 341-342.

Severens JL \& Milne RJ (2004) Discounting Health Outcomes in Economic Evaluation: The Ongoing Debate. https:// onlinelibrary.wiley.com/doi/full/10.1111/j.1524-4733.2004.74002.x

Sharma A, Kumar S (2010) Economic value added (EVA) - literature review and relevant issues. Int J Econ Financ 2(2):200-220

Singh P (2005) EVA in Indian Banking: Better Information Content, More Shareholder Value. ABHIGYAN XXIII(3):40-49

Steiger $F(2010)$ The validity of company valuation using discounted cash flow methods. Papers1003.4881, arXiv.org

Stewart GB (1991) The quest for value: a guide for senior managers, 1st edn. Harper Business, New York

Thomas LG, D'Aveni RA (2009) The changing nature of competition in the US manufacturing sector, 1950 to 2002. Strateg Organ 7(4):387-431

Tiwari KN (1994) Single versus multiple discount rates in investment theory. J Mult Discount Rates Investment Theory 7(2):19-42

Tully S (1993) The Real Key to Creating Wealth. Fortune 128(6):38-50

Turvey CG, Meilke K, Weersink A, Clark S, Klein K, Sarker R (1995) Measuring the capitalization of income transfer programs into agricultural asset values. Agriculture and Agri-food Canada. Available: http//dsp-psd.pwgsc.gc.ca/Collection/A21-49-1995-4E.pdf [2008 June 8]

Worthington AC, West T (2004) Australian Evidence Concerning the Information Content of Economic Value-Added. Australian Journal of Management 29(2):201-224

Young D (1999) Some Reflections on Accounting Adjustments and Economic Value Added. Journal of Financial Statement Analysis 4(2):7-19

Zhao X, Wang T (2012) Economic value added for performance evaluation: a financial engineering. Systems Engineering Procedia 5:379-387

\section{Publisher's Note}

Springer Nature remains neutral with regard to jurisdictional claims in published maps and institutional affiliations. 